\title{
AC 2007-1634: WORKING EFFECTIVELY WITH GRADUATE STUDENTS
}

\section{Noel Schulz, Mississippi State University}

Noel N. Schulz received her B.S.E.E. and M.S.E.E. degrees from Virginia Polytechnic Institute and State University in 1988 and 1990, respectively. She received her Ph.D. in EE from the University of Minnesota in 1995. She has been an associate professor in the ECE department at Mississippi State University since July 2001 and holds the TVA Endowed Professorship in Power Systems Engineering. Prior to that she spent six years on the faculty of Michigan Tech. Her research interests are in computer applications in power system operations including artificial intelligence techniques. She is a NSF CAREER award recipient. She has been active in ASEE and is currently the Women in Engineering Division Chair. She is also active in the IEEE Power Engineering Society and is serving as Secretary for 2004-2007. Dr. Schulz is a member of Eta Kappa $\mathrm{Nu}$ and Tau Beta Pi.

\section{Kirk Schulz, Mississippi State University}

Kirk H. Schulz is currently the Interim Vice President for Research and Economic Development at Mississippi State University in Starkville, Mississippi. He received his B.S. and Ph.D. in Chemical Engineering from Virginia Polytechnic Institute and State University (Virginia Tech) in 1986 and 1991, respectively. Dr. Schulz has been on the faculty at the University of North Dakota, Michigan Technological University, and Mississippi State University. In addition to his responsibilities as Interim Vice President, he is a tenured Professor of Chemical Engineering, and is the holder of the Earnest W. and Mary Ann Deavenport, Jr. Endowed Chair, held by the Dean of Engineering at MSU. Dr. Schulz has been an active participant in chemical engineering education, and was selected as a Fellow for the American Association for the Advancement of Science (AAAS) in 2007 in recognition for contributions made to chemical engineering. He has held a variety of offices within the American Society for Engineering Education in both the New Engineering Educators and Chemical Engineering Divisions, and has remained active in presenting educational work at the ASEE National Meeting related to faculty development and graduate student mentoring. Kirk was awarded an NSF CAREER Development Award from the NSF in 1995, and has remained an active researcher during his tenure in academic administration. $\mathrm{He}$ is currently serving as the co-chair of the 2007 Chemical Engineering Summer School, to be held in Pullman, Washington during August of this year. 


\title{
Working Effectively with Graduate Students
}

\begin{abstract}
You have started your faculty position and you have your first graduate student. You have not had much management experience, you are writing proposals and trying to get results. How do you effectively manage graduate students? What size group is right for you? What should be the mixture of Ph.D./M.S. students? Can you use undergraduates in a research program?

This paper will address tips for working with graduate students individually and in groups. Advice on building and maintaining your group will be discussed. Additional advice on getting the most potential out of different types of students will also be included. Some scenarios and sample examples of challenges and solutions will be provided. The authors share over 15 years of experience of dos and don'ts with graduate students.
\end{abstract}

\section{Introduction}

Working with graduate students is part of the expectation for faculty members at any research university. However, many new faculty members find working with graduate students to be both bewildering and highly rewarding - and sometimes the most stressful part of starting their careers as academic faculty members.

The co-authors have advised over 40 graduate students during the past decade, and have learned several valuable lessons on working with graduate students. The comments and suggestions in this paper are not gleaned from formal research, but instead are common themes we have used in working and mentoring our students. References [1-5] also provide suggestions and additional ideas related to working with graduate students.

\section{General Tips for Working with Graduate Students}

\section{$\underline{\text { Be selective but not picky in selecting your students }}$}

Many times, new faculty members start looking for the ideal graduate student - who had a 4.0 GPA from a top 10 engineering program, with exceptional oral and written communication skills and experience doing undergraduate research. They will then pass up very strong students who have a significant amount of desire, but may not possess all of the desired characteristics. Clearly, there are some basic level skills that graduate students will need to do a particular research project, but a significant number of these skills can be made up for by hard work and enthusiasm for a research project.

\section{$\underline{\text { Treat the graduate students as a junior colleague }}$}

It is important to set clear standards and expectations for your students. We have both tried to treat our students as colleagues, which includes things like allowing them to choose when they come and go from work, when they take vacations and breaks, ensuring that they have everything they need to do their jobs successfully, and in general developing a relationship in 
which student and advisor are partners. While this seems easy in principle, it can be hard to always do in practice. For new graduate students, inevitably there will be several conversations about working together as partners, and that graduate school needs to be treated as seriously as a full-time job in industry. Even though there will be a few inevitable "bumps in the road" when giving graduate students freedom and flexibility, we have found that in the long run, graduate students are much more productive when feeling they are an integral part of the research team.

\section{Develop an appropriate mix of Ph.D. and M.S. Students}

The mixture of M.S. and Ph.D. students in your research group is a critical element. Some engineering disciplines may not have significant numbers of M.S. students enrolled in the program (such as many Chemical Engineering programs) and may strongly emphasize doctoral students. On the other hand, Computer Science and Electrical Engineering still have significant numbers of M.S. students, which may be a precursor to admittance to a doctoral program.

Generally, the type of project will determine whether or not you can (or want) to put a doctoral student on it as a dissertation project. As an example, many industry sponsored research projects are shorter in duration, and may not be appropriate for a dissertation project. If your research program is predominantly funded with shorter-term industrial support, you may have a much larger number of M.S. students. However, if you have a significant amount of federal support, or are using university funds, a doctoral student may be more appropriate.

Whenever possible work to stagger your group so you do not start a large group or graduate a large group at the same time. Overlapping students can provide training and quicker pick-up of topics. A large group of new students will be a big drain on your time. If you can use returning students to help train new students, it will help them learn to mentor and help you spread your time around the research group.

\section{Determine your optimal group size}

Early in your career, avoid growing your research group to too large a size. It is important that you don't have too many students so that you are not able to give each student the attention they need as they start their research programs. If you choose to be very intimately involved with each student's research project, you will need to keep your group smaller. However, if you tend to manage your research group and expect the graduate students to involve themselves more in the technical detail, you can manage a larger group of students. Regardless, it is important to choose how many students you feel comfortable with, and to stick with this number.

\section{$\underline{\text { Working with Larger Groups }}$}

If your group gets larger than six students, consider dividing it into sub-groups and meeting regularly with the sub-groups. Larger groups make it very difficult to meet individually with each student weekly. Sub-groups provide peer interaction and peer pressure to produce results. Additionally the sub-groups provide an audience for research presentations and discussions. Sub-groups can be grouped to combine $\mathrm{PhD}$, MS and undergraduate researchers. PhD students can be the group lead and develop leadership skills within the sub-group. 


\section{Turning Graduate Students into Professional Researchers}

\section{$\underline{\text { Proposal Writing Opportunities }}$}

Following graduation, many graduate students will be involved in writing proposals for projects in federal research laboratories, academia, and industry. It is critical that students get involved in learning to write proposals, or at least helping to write proposals, while in graduate schools.

\section{Journal Paper Writing and Paper Reviews}

Peer-reviewed journal papers are the academic currency of today at virtually all universities. As such, it is critical that graduate students learn the details of how papers are published. For new students in a research group, they can read over draft manuscripts and make suggestions and comments. When paper reviews are received, we have found it helpful to share these reviews with the students so that they can see the types of comments that are typical following the blind, peer-review process. By involvement of students throughout the process, when it comes time for them to write their first journal paper, they are familiar with the process of submitting their work for publication in a journal.

\section{$\underline{\text { Professional Presentations }}$}

Graduate students need to make technical presentations as often as possible. While it may not be possible for all of your graduate students to make a presentation at a national meeting, there are a significant number of regional, local, and statewide conferences that can also give students valuable experience in presenting their project (or their proposed project).

As an example, many states have an annual meeting of the [Fill in Your State] Academy of Sciences. This is often a very low key meeting which has a poster session, which can be an excellent venue for graduate students to get an initial experience in presenting their work. Additionally, there are often regional meetings (such as the regional ASEE meetings) that also have some venues for graduate students to present their work. Finally, many national professional meetings also have travel support available for graduate students presenting their work, which can be a very cost effective way to give your graduate students experience presenting their work.

\section{$\underline{\text { Development of Social Skills }}$}

Many graduate students have not fully developed social and networking skills that will be critical in their future careers. As such, we have found that it is important to discuss appropriate meeting and professional attire, networking skills, and dining etiquette with graduate students prior to attending a professional function. It is an embarrassing situation for both the advisor and the student when they show up wearing blue jeans and a t-shirt to make a presentation at a meeting, only to see everyone else with professional attire. Additionally when working with international students, it is important to outline etiquette and American customs that others may take for granted. 


\section{What They Don't Tell You in Graduate School - Academic Parenting}

Provide planning, expectations, and guidelines

As an advisor, it is important to develop clear guidelines and expectations for students. Appendix A gives some guidelines one of the co-authors has used with her graduate students. By putting this information in writing and providing it to the students, this helps the graduate students to understand more clearly what is expected of them. Similar documents can be developed for journal paper preparation or other common tasks associated with your research program.

Be Patient - Students take time to develop

It is especially important to be patient with new graduate students who are just starting on a project. There is a significant difference between the research abilities between a doctoral student in their final semester and a master's student in their first semester. It can take students a couple of semesters to learn to balance their research project with their coursework. Often, new students will over emphasize their coursework and under emphasize their research project - an attitude that is often carried over from their time as undergraduate students. However, what is more important is for students to make improvement each semester in their time management and research skills, which often will require patience and understanding on the part of the advisor.

\section{$\underline{\text { Each Student is Different - Learn to Work with the Differences }}$}

Even though we have advised a significant number of graduate students, one characteristic ranks above all others - each student is different! Some students will have better skills in one area or another, some will have better time management skills, some will consistently perform under their ability, and some will perform over their ability. As a research advisor, it will be important to learn each student's strengths and weaknesses, and to find ways to assist them in fully developing their individual skill sets. However, do not compare your students to each other publicly or privately - this will only cause conflict in your research group.

\section{Common Challenges and Suggestions}

The next section provides several situations and some suggestions on dos and don'ts to help you with working with graduate students.

\section{Couples - Double Trouble or Two for the Price of One?}

Often within graduate programs, women faculty attract women students, minority faculty attract minority students and in our case, dual career faculty attract dual career students. In 11 years, one of us has worked with at least one partner in eight dual engineering graduate student couples. This provides challenges and opportunities. 
Issue: Graduate student Susan Smith comes in and tells you that her husband, Tom Smith has been admitted to your department but does not have funding. This will put a strain on the family budget as they have to pay tuition.

Suggestion: Investigate the rules related to paying tuition for graduate students. We have worked with couples to split the original stipend level but provide two tuitions for one semester. In most cases the trailing graduate student has become a fully funded graduate student for one of a colleague or us. This relieves the financial issues for your student, creates a feeling of loyalty to you and often provides an extra graduate student.

Issue: Husband and Wife are working on related project and one comes to talk to you about the other.

Suggestion: Work to treat the graduate students as individuals and not one entity. Try not to deliver messages to one spouse/partner for the other. Don't let the spouse talk for the other student. If things become a problem, consider having a meeting with both students to talk about the ground rules.

Issue: Partners are working in your group and do not interact with other graduate students. Suggestion: Separate the partners/spouses' working space. Also talk to them about the importance of being a team member and not seeming to only work together.

Issue: Husband and Wife are working on a related project. In publications and presentations it is difficult to tell the contributions of each person.

Suggestion: Early on in their graduate programs sit down with the couple and discuss the issues of working together. Discuss the benefits of mutual discussions but the importance of each individual's contributions being identifiable and defendable. You do not want someone failing their oral because they have relied too much on their spouse's intellect and don't really understand the work. This can especially be a problem when the spouses are pursuing different degrees (MS and $\mathrm{PhD})$.

Large Groups - How to give individual feedback and attention to larger research groups

Issue: You are the PI on a large project that involves several research faculty or post-docs and a bunch (greater than you can handle individually) of graduate students. You do not have time to meet with the graduate students individually weekly.

\section{Suggestions:}

1) As mentioned above, break the groups into sub-groups and have weekly or biweekly meetings with the sub-groups. Appoint a research faculty member, post-doc or PhD student as the lead of the group to help in professional development. During this meeting have each student give a several minute update or one page summary of his/her accomplishments the last week or two weeks. Discuss issues, barriers and needs.

2) Consider providing regular feedback to the graduate students on their performance compared to their potential and other graduate students. Give them some ideas of things they are doing well and things they need to improve on. This could be done every semester. This is also an avenue to document the poor performance of graduate students so you can fire them if they continue to perform below expectations. Appendix B shows a one page letter to one student that explains the grading system and evaluation. 
$\underline{\text { Industrial Research - Helping Students Learn About the Real-World }}$

Issue: You do not have industrial experience and everyone seems to feel this makes you a better faculty member. How do you get involved in industrial research without contacts and help your graduate students get jobs after they finish their programs?

Suggestion: Graduate internships are win-win opportunities for you to get your foot in the door and have your graduate students learn about the real world. Many times companies and universities focus on undergraduate internships and co-operative positions. However, there are a wealth of opportunities in the graduate intern area ${ }^{6}$. Graduate students are more mature and can get more accomplished in three months. Additionally this give you an in to visit the company. Many times these internships have turned into small industrial contracts where the same student continued an extension of his/her work on campus. Eventually the contracts can grow bigger. This is a great way to build a relationship with a company and give the students industrial experience. One word of caution - Try to make sure that your first student at a company is very good. A good student can open up opportunities for many in the future, while a poor student can close the door for a while. Also work to match the student's personality with the company.

\section{$\underline{\text { Cultural Melting Pot or Small Groups of Researchers from Different Countries }}$}

Issue: As your group grows larger, there tend to be small subgroups of graduate students from the same country. These students stick together sometimes creating friction between various students within your overall research group. How do you get them to interact more as a single group, rather than by their country of origin?

\section{Suggestions:}

One of our research groups currently has faculty and students from five continents providing a diverse population. However, as you get a critical mass of students from one area or country, these students tend to study together and talk together, sometimes making others feel left out. This relationship is positive especially in helping new graduate students feel comfortable with their new setting. However, it can become a problem.

1) Demand that only English should be spoken within the research lab and research discussions. English is the common language for all the students. While some students find it easier to communicate with other students from their country in their native language, this has several detrimental effects. First typically these students speak their native language at home or outside the lab. If they don't practice their English communication skills in the research lab, their skills may not improve and may be a barrier for their jobs in the future. Second it can cause hard feelings between the students if someone thinks one is talking about the other. This can hurt the group dynamics.

2) Find avenues for each of the cultures to share information and activities about their own culture. Encourage students to invite each other to local events related to their country or culture. Have a potluck dinner at your house where everyone brings a food of choice. Host a baby shower for an expecting graduate student or spouse and have each person talk about traditions within his/her country related to babies. Throw a birthday party and have each student sing or write a birthday greeting in his/her language. Celebrate and share your differences. 
3) Encourage one of the outgoing graduate students to provide a bridge between the different groups of students. This works particularly well if the outgoing student is the only one from his/her country.

Technical Communications with Graduate Students - Like a trip to the dentist, sometimes painful!

Issue: Your graduate student just handed you a draft of the first chapter of his/her dissertation or a presentation and it is not well done. You are going to have to spend a lot of time to improve it.

\section{Suggestions:}

1) Start students writing and presenting as soon as they get into your group to help them get more comfortable with presentations and writing. Require periodic progress reports or a short report on their literature survey that are short where you can provide feedback to help with later papers.

2) Use the sub-group meetings or weekly group meetings as an opportunity for each graduate student to present at least one time every semester. Encourage the graduate students to provide constructive suggestions. Have the graduate students do a practice presentation without any faculty there. Some students are more willing to ask questions with only graduate students there and this helps everyone improve their presentation and technical question skills.

3) Push your graduate students to present at local poster sessions. Many schools have a graduate student association or Engineering Week poster presentation. Push students to participate in these. These help display your research to colleagues at your university and also provide outlets for students to pull together their work in a clear, concise manner.

4) Provide guidelines related to writing activities such as theses, dissertations and papers. The more guidelines you provide up front, the less work you will have along the way. Have examples of well done presentations and papers for graduate students to follow. Encourage new graduate students to participate in final defense presentations of other students so they can see presentations and understand the process and expectations ahead of time.

5) With larger groups, pay an English graduate student or undergraduate to be the first reader for papers, theses, dissertations or reports. Have him/her work with your graduate students on common mistakes. Some units might have this as a resource. Even if you do not have university funds to pay for this, consider even paying someone out of your own pocket. The money will be well spent as you will spend a lot less time doing grammar, spelling and subject/verb corrections.

\section{Summary}

The relationships developed between graduate students and their faculty advisor is part of what makes working at a university so rewarding. We have offered several tips that we believe will assist faculty members in working effectively with their graduate students. Faculty members have their own style and will need to adapt these suggestions to fit with their personality and comfort zones. The diversity of styles provides an additional educational opportunity for students. 


\section{References}

1. Julie L.P. Jessop, "How to Grow Your Graduate Students: Mentoring Tips for New Professors," Proceedings of the 2003 ASEE Annual Conference, 2003.

2. [P.C. Wankat, The Effective, Efficient Professor: Teaching, Scholarship and Service, Allyn and Bacon, Boston, 2002.

3. [C.I. Davidson and S.A. Ambrose, The New Professor's Handbook, Anker Publishing, Inc. Bolton, MA, 1994.

4. Richard Reis, Tomorrow's Professor: Preparing for Careers in Science and Engineering, Wiley-IEEE Press, 1997.

5. Robert Boice, Advice for New Faculty Members, Allyn and Bacon, Boston, 2001

6. Yamilka Baez-Rivera, Lennon Brown III and Noel N. Schulz, "Using Graduate Internships to Enhance Graduate Student Education and Research," Proceedings of the 2007 ASEE Annual Conference, 2007, in press. 


\section{Appendix A}

\section{Guidelines for Writing Your Thesis/Dissertation}

Your thesis/dissertation has two purposes.

1) Document your work

The thesis/dissertation is supposed to provide a comprehensive overview of your research work. It should introduce the topic and problem to the reader, explain what previous work has been done related to the topic, outline your approach, document your techniques and methods, detail the data and results and provide conclusions and ideas for future work.

2) Provide background for the next student(s)

Your thesis/dissertation is also a teaching tool. It helps provide a complete package of information on the topic for the next student. It should be written so any undergraduate in EE can understand the introductory and background part.

It works best for me if we can review your document in chapters. This allows me to give you some quicker feedback. Also remember to have the chapter reviewed by the English editor before giving it to me. That way I can concentrate on the technical content instead of the grammar.

Start writing early. It is much easier to edit than to create. Take a couple hours each week and write even early in the process and it will pay off with a much better document in the end.

Chapters of the Thesis/Dissertation (subject to change depending on your topic)

\section{Chapter 1: Introduction}

This chapter is usually 3-5 pages and provides an introduction into the problem and why we need to solve it. This should convince the reader that it is a useful problem to solve. The end of the chapter should include a thesis statement that states what you did and a short summary of the results. Additionally the end of this chapter usually provides an outline for the other chapters.

\section{Chapter 2: Background/Literature Review}

This material is sometimes broken into two chapters depending on your topic. Background provides an overview of the main topics/areas covered in your research. This can be techniques, tools, definitions and explanation of key terms.

For the literature review, it is important to show others that you understand what has already been done and to show how your research fits into previous work. In this section you discuss key pieces of work that relate to your research. Give a sentence or two about each key reference and what contribution it made.

At the end of this chapter you should provide a summary of what is missing from the literature (your work) and how the proposed project will solve this problem. 


\section{Chapter 3: Problem Statement and Proposed Solution}

This chapter should provide a statement for what problem you have solved and what tools/methods/algorithms were used to solve the problem.

Chapters 4-6 may be different depending on your work. You may be able to combine them into two chapters divided as appropriate.

\section{Chapter 4: Test Cases/Data/Tools}

This chapter will discuss the type of data you need to do the project, any test cases, especially standard test case, that you plan to use and will document any tools or equipment that will be used. This chapter should also include information about the versions of software or hardware including type of computer used. This may be important if some of your results relate to a time to run a simulation. Give a summary explanation of the sample data and an overview of the test cases. If there is lots of data consider putting it in the appendices.

For the tools, you need to provide the reader with an explanation on why certain software or hardware works well for solving this problem.

\section{Chapter 5: Approach/Algorithm/Analysis/Design}

This chapter is really the meat of your contribution. This chapter should include what new and improved thing you have done. You should provide flow charts for algorithms explaining different branches within your work. Here is where you may provide equations and solutions. How did you solve the problem? What problems did you run into? What things did you try that succeeded and failed?

\section{Chapter 6: Results and Discussion}

This chapter shows the results of combining the parts of chapter 4 with the parts of chapter 5 . The results should be a summary of the data. You should find ways to do charts, graphs or tables that summarize different cases. Explain your results along the way. Don't make the reader figure them out. Discuss the figures and tables to demonstrate to the reader how your approach has solved the original problem. Point out any discrepancies and offer an intelligent guess on why that might have happened.

\section{Chapter 7: Conclusions and Future Work}

This chapter is two parts. The first part, Conclusions, should be a summary of the entire work and should also outline your major contributions to the state-of-the-art. Be specific on your contributions. Don't be modest but also don't claim you did things you didn't.

The Future Work section should discuss additional work that can be done related to the topic that would be useful to advance your work. This may be extensions or parallel ideas.

\section{References}

Use the IEEE format for references. Make sure you are consistent with the way you write names, dates, page numbers, etc. Start working on the references as you do the draft chapters and it will help make it go faster. 


\section{Appendices}

Appendices are where you put any extra detail that doesn't need to be in the document but would be helpful for someone understanding your work. You can show sample calculations, input/output files, raw data, extensive data on test cases and source code.

\section{Other things to remember}

1) Check out the guidelines on the University's Graduate School Webpage. $\mathrm{http}: / /$ www.msstate.edu/dept/grad/thesis_guidelines.htm

2) Always make it very clear on what work is yours and what work others have done. If you extend someone else's concepts, make sure to explain the extension.

3) Use pictures, tables, graphs or diagrams whenever possible to explain a point. A picture is worth a thousand words and takes a lot less time to do $:$

4) Always number the pages in drafts. It would also be helpful to put a date in the header or footer for drafts to make sure I am looking at the latest version.

5) In your individual chapters you can use shorthand for references [T. Smith, 2003] instead of worrying about numbering. This way you can do your numbering in the end.

6) Try to make figures and tables as large as possible to make them readable. Always refer to the figures within your text and give a brief description of what the graph means especially if it is complicated. Help the reader understand, do not assume $\mathrm{s} / \mathrm{he}$ can understand it.

7) Be consistent in labeling tables and figures, on the caption and in the text. Label the figures $2.1,2.2$, etc where the first number is the chapter.

8) If you have a lot of acronyms, put a list of acronyms and meanings in the front so that the reader can refer to them.

9) Each chapter should have an introduction and summary. The introduction should explain what will be covered in the chapter. The summary should discuss what was covered in the chapter and can sometimes create a bridge to the next chapter.

10) The thesis/dissertation is a summary document of your work. You should not have extensive amounts of data or examples within the text. If you have some important input, output, code or other important raw data include that in the Appendices. Many faculty on committees like to see the code in the appendix.

11) Avoid I or we in your document. You may need to use passive voice in the document and that is okay (although the English reviewer may encourage you to use active voice).

12) Start working early on the "extra pages", when you are tired and need a break from writing. This includes the title page, abstract, acknowledgements, table of contents, etc. See the guideline webpage listed above in 1).

13) Work with Dr. XXXX to get at least one (or two for PhD students) journal paper published on your work!!!! 
Appendix B - Example review form

TO: $\quad$ Student $\mathrm{X}$

FROM: $\quad$ Faculty Y

DATE: $\quad$ March 7, 2007

\section{SUBJECT: Mid-Semester Review and Suggestions}

Based on your activities last semester and the start of this semester your research progress is recorded as a $\mathrm{B}^{+}$.

Students are graded on the following scale:
A - Exceeds Expectations
B - Meets Expectations
$\mathrm{C}$ - Needs Improvement

If you received a + or - , this means that your performance is between the two letter grade with the emphasis on the letter grade and the $+/$ - as additional information. This scale relates to the student's effort, performance and output for research activities. We will also consider your potential research capabilities and how you are working toward those.

These are your areas of strength:

1. Organized research activities 2. Excellent presentation and writing ability 3 . Team leader within sub-group and all graduate students.

These are your areas for improvement.

1. Additional focus on research activities, especially technical details. 2. More accessibility in office for collaboration and discussions.

Please review this document. If you have any questions, please discuss with your advisor. Please sign this document and return a signed copy to me by March 9, 2007.

The faculty looks forward to working with you to help you reach your research goals as well as contribute to the Power and High Voltage Group.

I have reviewed the above information. 